\title{
Robert Watt*
}

\section{Three Myths About Kant's Second Antinomy}

\author{
https://doi.org/10.1515/agph-2019-2006
}

\begin{abstract}
This article challenges three widespread assumptions about Kant's argument for the antithesis of the Second Antinomy. The first assumption is that this argument consists of an argument for the claim that "[no] composite thing in the world consists of simple parts", and a logically independent argument for the claim that "nothing simple exists anywhere in the world". The second assumption is that when Kant argues that "[no] composite thing in the world consists of simple parts”, he is making a claim about the mereological structure of spatially extended things in particular, as opposed to a claim about the mereological structure of things in general. And the third assumption is that Kant's argument for this part of the antithesis is based on a claim about the relationship between the size of the extension of a composite thing and the sizes of the extensions of the things of which this composite thing consists.
\end{abstract}

\section{Introduction}

In the Second Antinomy, Kant puts forward a pair of arguments. One is for the thesis that "[every] composite substance in the world consists of simple parts, and nothing exists anywhere apart from the simple and what is composed of the simple" (A434/B462); the other is for the corresponding antithesis that "[no] composite thing in the world consists of simple parts, and nothing simple exists anywhere in the world" (A435/B463). ${ }^{1}$ Kant believes that both of these arguments are sound if transcendental realism is true and that neither of these arguments is sound if transcendental realism is false. ${ }^{2}$ Since he believes that at most one of

1 All translations in this article are my own. All references to the Critique of Pure Reason take the standard A/B form. All references to Kant's other works are to the Academy Edition.

2 In the Prolegomena Kant writes: "if [...] we think of the appearances of the sensible world as things in themselves [...] both thesis and antithesis can be established by equally clear and compelling proofs" (4:339-340). He adds: "I vouch for the correctness of all these proofs" (4:340).

*Corresponding author: Robert Watt, Department of Philosophy, University of Oxford, Trinity College, Oxford, OX13BH, UK; robert.watt@philosophy.ox.ac.uk 
these arguments is sound, he concludes that transcendental realism is false and that neither of these arguments is sound. ${ }^{3}$

My aim in this article is to challenge three widespread assumptions about Kant's argument for the antithesis of the Second Antinomy. These assumptions stand in the way of a proper assessment of Kant's belief that this argument is sound if and only if transcendental realism is true. They also mask the relevance of this argument to more recent philosophical debates about the mereological structure of space and the mereological structure of spatially extended things. The first assumption is that Kant's argument for the antithesis of the Second Antinomy consists of an argument for the claim that "[no] composite thing in the world consists of simple parts", which I shall call A1, and a logically independent argument for the claim that "nothing simple exists anywhere in the world", which I shall call A2. I shall argue in Section 2 that this assumption is false. In particular, I shall argue that it is possible to solve two puzzles about the structure of Kant's argument for A2 if we accept that this argument is logically dependent upon Kant's argument for A1.

The second assumption that I shall discuss in this article is that A1 should be interpreted as a claim about the mereological structure of spatially extended things in particular, not as a claim about the mereological structure of things in general. I shall argue in Section 3 that this assumption is based on a failure to appreciate the fact that Kant's argument for A1 takes as its starting point the principle that every composite thing in the world is spatially extended. From this principle it follows that if no composite and spatially extended thing in the world consists of simple parts, no composite thing in the world consists of simple parts.

In Section 4, I shall turn to the third assumption, which is that Kant's argument for A1 is based on a claim about the relationship between the size of the extension of a composite thing and the sizes of the extensions of the things of which this composite thing consists. This claim, which is also one of the premises of Pierre Bayle's argument against spatially extended things in his famous article on Zeno of Elea, is that it is impossible to make a composite substance the size of the extension of which is strictly greater than zero out of any number of substances the size of the extension of which is zero. I shall argue in Section 4 that there is no textual evidence to support this assumption. I shall also argue that it is based on a misinterpretation of Kant's concept of spatial extension.

In the course of this article I shall make use of a few technical mereological notions. One is the notion of a proper part. A thing $x$ is a proper part of a thing $y$

3 This is the indirect proof of transcendental idealism to which Kant refers in the seventh section of the Antinomy of Pure Reason (A506-507/B534-535). 
if and only if $x$ is a part of $y$, and $x$ and $y$ are numerically distinct. Another is the notion of overlapping. A thing $x$ overlaps a thing $y$ if and only if there is a thing $z$ that is both a part of $x$ and a part of $y$. And a third is the notion of a mereological fusion. A thing $x$ is a mereological fusion of some things $y, z$, etc. if and only if every one of $y, z$, etc. is a part of $x$, and every part of $x$ overlaps at least one of $y, z$, etc. ${ }^{4}$ Like most other commentators on the Second Antinomy, I shall assume that what Kant means by a composite thing is a thing that has something as a proper part, and that what he means by a simple thing is a thing that has nothing as a proper part. ${ }^{5}$ I shall also assume that what Kant means by a thing in the context of the Second Antinomy is a substance. ${ }^{6}$

One important question about the Second Antinomy that has not received the sort of attention it deserves is what exactly Kant means by the claim that a composite substance consists of simple substances. According to one recent interpretation, a composite substance consists of simple substances if and only if it has a simple substance as a part. ${ }^{7}$ But there is a serious objection to this interpretation. Surely, Kant would not accept that my body consists of my arms. But he would accept that my arms are parts of my body. So he cannot think that a thing $x$ consists of some things $y, z$, etc. if and only if $x$ has one of $y, z$, etc. as a part. There is a more plausible interpretation according to which a composite substance consists of simple substances if and only if it is a mereological fusion of simple substances. ${ }^{8}$ But this interpretation is also open to a serious objection. It is perfectly possible for a composite substance that is a mereological fusion of simple substances to be infinitely divisible. A thing is infinitely divisible if and only if it has something as a proper part, which has something as a proper part,

4 Lewis writes: "[something] is a fusion of some things iff it has all of them as parts and has no part that is distinct from them" $(1991,73)$. Van Inwagen prefers the term "sum". He writes: " $y$ is a sum of the $x \mathrm{~s}=\mathrm{df}$ the $x \mathrm{~s}$ are all parts of $y$ and every part of $y$ overlaps at least one of the $x \mathrm{~s}$ " $(1990,29)$.

5 Cf. Falkenburg 2000, 227, Malzkorn 1998, $171 \mathrm{f}$.

6 There is plenty of textual evidence for this. Consider the first part of the thesis of the Second Antinomy, i.e., "every composite substance in the world consists of simple parts" (A434/B462). Kant also makes it clear in the course of his argument for A1 that what is at stake is the composition of substances: "[since] all external relation, therefore all composition of substances, is only possible in space [...]” (A435/B463).

7 Malzkorn 1999, 173, Falkenburg 2000, 228. Malzkorn and Falkenburg formalize A1 by the sentence $\forall x\left(\exists y(y<x) \rightarrow \neg \exists z\left((z<x) \wedge \neg \exists x_{1}\left(x_{1}<z\right)\right)\right)$, where the domain of discourse is the set of substances in the world, and the formula $(\mathrm{x}<\mathrm{y})$ is interpreted: $\mathrm{x}$ is a proper part of $\mathrm{y}$.

8 If this interpretation is correct, A1 can be formalized by the sentence $\forall x\left(\exists y(y<x) \rightarrow \neg \forall z\left(z \leq x \rightarrow \exists x_{1}\right.\right.$ $\left.\left(x_{1} \leq z \wedge \neg \exists y_{1}\left(y_{1}<x_{1}\right)\right)\right)$, where $(x \leq y)$ is interpreted: $x$ is a part of $y$. 
which has something as a proper part, and so on to infinity. ${ }^{9}$ But there is evidence that, as far as Kant is concerned, if a composite thing consists of simple parts, it is not infinitely divisible. At the beginning of his Remark on the Antithesis of the Second Antinomy, Kant identifies A1 with the "assertion of an infinite division of matter" (A439/B467). So he clearly thinks that if substance is infinitely divisible, it does not consist of simple parts. But in that case he cannot think that a thing $x$ consists of some things $y, z$, etc. if and only if $x$ is a mereological fusion of $y, z$, etc. In this article I shall assume that a composite substance consists of simple substances if and only if it is both a mereological fusion of simple substances and also not infinitely divisible. This interpretation is undoubtedly anachronistic. But I suggest that it is also the simplest way to express with any degree of precision what Kant means in the Second Antinomy by a composite substance that consists of simple substances.

\section{The Structure of the Argument}

The antithesis of the Second Antinomy is the conjunction of the following claims:

A1 There is no composite substance in the world that consists of simple substances.

A2 There is no simple substance in the world.

There is no question that A1 is entailed by A2. Suppose that A1 is false. Suppose that there is a composite substance in the world that consists of simple substances. Then there must be some simple substances in the world. So A2 must be false. So if A2 is true, A1 must be true. There is a passage in Kant's Remark on the Antithesis of the Second Antinomy where he draws attention to this fact about the relationship between A1 and A2. He writes that "[the] second clause of the antithesis goes much further than the first, which banishes the simple only from the intuition of the composite, since [the second] takes it away from the whole of nature" (A437/B465). ${ }^{10}$

9 Suppose that a composite thing has as proper parts both a simple thing and also a composite thing that has as proper parts both a simple thing and also a composite thing that has as proper parts both a simple thing and also a composite thing, and so on to infinity. Suppose that this composite thing has no other proper parts. It is then a mereological fusion of simple things. But it is also infinitely divisible.

10 It is widely accepted that A1 is entailed by A2. Falkenburg writes that A2 is "stronger than" A1, since A1 "rules out that there are composite substances that have simple parts, but allows that there are simple substances that are not parts of a whole" (2000, 228). Malzkorn writes that, 
Now Kant's argument for the antithesis of the Second Antinomy consists of a pair of arguments. The first, which is carried out in the first paragraph of Kant's discussion, is an argument for A1, and the second, which is carried out in the second paragraph of Kant's discussion, is an argument for A2. It is commonly assumed that these arguments are logically independent in the sense that neither has as one of its premises the conclusion of the other. Some commentators make the point explicitly. Malzkorn writes that "[in] the proof of the antithesis, both assertions [i.e. A1 and A2] are argued for independently of one another". ${ }^{11}$ Engelhard writes that "the second proof of the antithesis is dependent in terms of its content on the first", but she also writes that the arguments are independent "considered formally". ${ }^{12}$ What she means by this is that although Kant's argument for A2 shares a premise with his argument for A1, it does not have A1 as one of its premises. ${ }^{13}$ Other commentators clearly make the same assumption since they do not mention A1 in their reconstructions of Kant's argument for A2. ${ }^{14}$

There is good reason to think that this assumption is false. Suppose it is true that Kant's argument for the antithesis of the Second Antinomy consists of an argument for A1 and a logically independent argument for A2. In that case, Kant's argument for A1 is redundant, since A1 is entailed by A2. But this creates a puzzle. Why does Kant put forward a redundant argument for A1? Why doesn't he just put forward his argument for A2 and then note that if A2 is true, A1 is true? The fact that he doesn't do this is especially puzzling in light of the structure of Kant's argument for the thesis of the Second Antinomy, which is also the conjunction of a pair of claims:

according to Kant, A2 is "a logically stronger assertion" than A1, since A1 "only asserts that there is no composite thing that consists of simple parts, and so leaves open at least the possibility that there are simple things", while A2 "denies also the existence of such things" (1998, 169). Broad writes that A2 is "much stronger" than A1, since A2 "says that there are no simple substances at all, and not merely that no extended substance is composed of simple substances" $(1954,20)$. Guyer describes A2 as a "more general claim" than A1 (1987, 410). Radner 1998, 429, and Van Cleve 1999, 65 f., ignore A2 entirely.

11 1998, 169.

12 2005, 205.

13 The premise that Engelhard thinks is common to Kant's arguments for A1 and A2 is that every spatially extended substance is a composite substance $(2005,224)$. Grier also thinks that this is a premise of both arguments (2001, 207 f.).

14 As Engelhard 2005, 223, points out, some commentators simply ignore the second argument. These commentators include Falkenburg 2000, 236, Grier 2001, 207, Van Cleve 1999, and Radner 1998. 
T1 Every composite substance in the world consists of simple substances.

T2 Every substance in the world is either a simple substance or a composite substance that consists of simple substances.

Kant's argument for the thesis doesn't consist of logically independent arguments for T1 and T2. And there is an obvious explanation for this. As Kant points out (A436/B464), T2 is entailed by T1, which means that a logically independent argument for T2 would be redundant. ${ }^{15}$ So Kant just puts forward an argument for $\mathrm{T} 1$ and then notes that if T1 is true, T2 is true. But if Kant doesn't put forward a logically independent argument for T2, because T2 is entailed by T1, why does he put forward a logically independent argument for A1, when A1 is entailed by A2?

I suggest that Kant's argument for A2 in the second paragraph of his discussion of the antithesis is not logically independent of his argument for A1 in the first paragraph. More precisely, I suggest that one of the premises of Kant's argument for A2 is a corollary of A1, viz. that if there is a simple substance in the world, it is not a part of a composite substance that consists of simple substances. To substantiate this position, it is necessary to look in more detail at Kant's argument for A2. The argument has three premises. The first premise is that a simple substance counts as an object of possible experience only if it is possible for us to have an empirical intuition of it. As Kant puts it, "if we were to assume that an object of experience is to be found for this transcendental idea [i.e. the idea of simple substance], the empirical intuition of some object as such [i.e. as simple] would have to be recognized, which contained absolutely no externally related manifold combined into a unity" (A437/B465). The second premise of the argument is that it is impossible for us to have an "empirical intuition" of a simple substance. In support of this premise Kant writes: "since there is no inference from the non-consciousness of such a manifold to the complete impossibility thereof in an intuition of an object, but the latter is entirely necessary for absolute simplicity, it follows that absolute simplicity can be inferred from no perception, whatever it may be" (A437/B465). The third premise of the argument is that there is a simple substance in the world only if a simple substance is an object of possible experience. To understand why Kant thinks that this third premise is true, it is important to notice that what he means by the world in the context of the Second Antinomy is the sensible world, the concept of which he clarifies in the

15 If every composite substance in the world consists of simple substances, every substance in the world that does not consist of simple substances is a simple substance, i. e., every substance in the world is either a simple substance or a composite substance that consists of simple substances. 
last sentence of the argument: "the sensible world must be regarded as the totality of all possible experience” (A437/B465). For Kant, what it means to claim that there is a simple substance in the world is that a simple substance is an object of possible experience. ${ }^{16}$

Consider the claim that a simple substance counts as an object of possible experience only if it is possible for us to have an empirical intuition of it - or, to put it another way, the claim that a simple substance counts as an object of possible experience only if it is possible to perceive this simple substance directly. There is a puzzle about this premise of Kant's argument. Kant doesn't think that it is true in general that something counts as an object of possible experience only if it is possible to have an empirical intuition of it. He thinks that it is perfectly possible for us to have experience of an object even if it is impossible for us to perceive this object directly. He gives a famous example to illustrate this point in his elucidation of the Second Postulate of Empirical Thinking in General: “we cognize the existence of a magnetic matter permeating all bodies from the perception of attracted iron filings, although a direct perception of this matter is impossible for us according to the constitution of our senses" (A226/B273). Kant thinks that it is impossible for us to have an empirical intuition of a "magnetic matter permeating all bodies". But he still thinks that it is possible for us to have empirical cognition of this magnetic matter, and that is as much as to say that this magnetic matter is an object of possible experience. According to Kant, what is necessary for something to count as an object of possible experience is not that it is possible for us to perceive this object directly, but rather that it is possible for us either to perceive this object directly, or to infer the existence of this object from the existence of some other object that it is possible for us to perceive directly. Kant thinks that this is how the magnetic matter counts as an object of possible experience. It is possible for us directly to perceive the motion of the iron filings when they are placed in the vicinity of a magnet, and to infer from this motion the existence of a magnetic matter permeating all bodies. What is puzzling about the first premise of Kant's argument in the second paragraph is that he completely ignores the possibility that a simple substance counts as an object of possible experience not because it is possible for us to perceive it directly, but rather because it is possible

16 This means that Broad is mistaken when he writes that Kant's claim that "the existence of the absolutely simple cannot be established by any experience or perception, either external or internal" (A437/B465) is an "entirely different assertion" to A2, which he interprets as the claim that "there are no simple substances at all" $(1954,20)$. A2 is in fact the claim that there are no simple substances in the world, and what Kant means by the world is the totality of all objects of possible experience. 
for us to infer the existence of this simple substance from the existence of some other object that it is possible for us to perceive directly.

I suggest that this aspect of Kant's argument for A2 makes sense if he is presupposing what he has established in his argument for A1, viz. that no composite substance in the world consists of simple substances, a corollary of which is that if there is a simple substance in the world, it is not a part of a composite substance that consists of simple substances. It is reasonable to assume that, as far as Kant is concerned, the only way to infer the existence of a simple substance from the existence of some other object that it is possible to perceive directly is by perceiving a composite substance and by inferring that this composite substance consists of simple substances on the basis of Kant's argument for T1. It is hard to think of any other way to make this inference. There is no obvious causal inference to the existence of simple substances from the existence of other objects that it is possible for us to perceive directly. If this is correct, Kant thinks that it is possible to infer the existence of simple substance from the existence of some other object that it is possible to perceive directly only if the simple substance in question is a part of a composite substance that consists of simple substances. If the simple substance in question is not a part of a composite substance that consists of simple substances, it is not possible to infer its existence from the existence of some other object that it is possible to perceive directly, which implies that this simple substance counts as an object of possible experience only if it is possible to perceive this simple substance directly.

I should mention that there is a possible objection to the argument that I have just made against the assumption that Kant's argument for A2 is logically independent of his argument for A1. I have assumed that Kant's argument for A2 fails to rule out the possibility that simple substance counts as an object of possible experience in the same way as magnetic matter. Now in the course of his discussion of magnetic matter, Kant indicates that magnetic matter counts as an object of possible experience because "according to the laws of sensibility and the context of our perceptions, we would come across the immediate empirical intuition of this stuff in experience if our senses were finer [...]" (A226/B273). One might conclude on this basis that an object that it is impossible for us to perceive directly counts as an object of possible experience for Kant as long as it is an object that it would be possible for us to perceive directly if our senses were more fine-grained. And one might think that Kant's argument for A2 does rule out the possibility that simple substance is something that it would be possible for us to perceive directly if our senses were more fine-grained, in which case there is no gap in Kant's argument for A2. This would undermine part of my argument against the assumption that Kant's argument for A2 is logically independent of his argument for A1. 
In response to this objection I would point out that Kant's discussion of magnetic matter comes in the middle of a passage where he clearly indicates that what is necessary for something to count as an object of possible experience is that it is possible either for us to perceive this object directly, or for us to infer the existence of this object from the existence of some other object that it is possible for us to perceive directly. Kant's talk of what it would be possible for us to perceive directly if our senses were more fine-grained must be interpreted in light of these other claims. A reasonable assumption is that, as far as Kant is concerned, the claim that an object is something the existence of which it is possible for us to infer from the existence of some other object that it is possible for us to perceive directly is equivalent to the claim that this object is something that it would be possible for us to perceive directly if our senses were more fine-grained. And if this is correct, it is reasonable to think that Kant's argument for A2 fails to rule out the possibility that simple substance counts as an object of possible experience because it satisfies this condition.

I conclude that Kant's argument for A2 turns on the assumption that if there is a simple substance in the world, it is not a part of a composite substance that consists of simple substances. It is precisely because Kant is relying on this assumption that he thinks he is entitled to ignore the possibility that simple substances count as objects of possible experience because it is possible for us to infer their existence from the existence of other objects that it is possible for us to perceive directly. Hence Kant's argument for A2 is not logically independent of his argument for A1. It is a presupposition of Kant's argument for A2 that A1 is true.

I have defended an interpretation of the structure of Kant's argument for the antithesis of the Second Antinomy according to which his argument for A2 is logically dependent upon his argument for A1. I have argued that this interpretation solves two puzzles about Kant's argument for the antithesis of the Second Antinomy. First, it explains why Kant includes an argument for A1 alongside his argument for A2 in spite of the fact that A1 is entailed by A2. Second, it explains why Kant's argument for A2 presupposes that if it is impossible for us to perceive a simple substance directly, simple substance is not an object of possible experience. Kant takes himself to have established in his argument for A1 that there is no simple substance that is a part of a composite substance that consists of simple substances. And so he takes himself to have ruled out the possibility that a simple substance counts as an object of experience because its existence can be inferred from the existence of some other object that it is possible for us to perceive directly, since he assumes that the only way to infer the existence of a simple substance from the existence of some other object that it is possible for us to perceive directly is by inferring its existence from the existence of a composite substance of which it is a part. 
There is a point about my argument in this section to which I want to draw particular attention. I have claimed that Kant's argument for the antithesis turns on the fact that he is only concerned with substances in the sensible world, i. e. substances that are objects of possible experience. This may be taken to mean that Kant is treating substances as mere appearances, not as things in themselves, in which case he is presupposing the results of the Transcendental Aesthetic. If my claim is interpreted in this way, it is open to a simple objection. There is plenty of evidence that Kant's aim in the Second Antinomy is to put forward arguments that would be accepted by transcendental realists, who treat substances as things in themselves. So how can his argument for the antithesis treat substances as mere appearances?

The crucial point for my purposes is that it doesn't follow from the fact that Kant's argument for the antithesis is only concerned with substances in the sensible world, i.e. objects of possible experience, that he is treating substances as mere appearances. I take it that what Kant is doing in the Second Antinomy is giving arguments based on the assumption that the objects of possible experience are things in themselves, contrary to the results of the Transcendental Aesthetic. He is treating substances in the same way as transcendental realists.

At this point, it may be objected that, according to the interpretation I have defended in this section, Kant's argument for A2 relies upon the Second Postulate, which is something that a transcendental realist would not accept. I agree that a transcendental realist would not accept the Second Postulate, but I do not think that, according to the interpretation that I have defended in this section, Kant's argument for A2 relies upon the Second Postulate. I have argued that Kant's argument for A2 relies upon an assumption about the conditions under which something counts as an object of possible experience; an assumption that is elucidated in Kant's discussion of the Second Postulate. But I do not think that this assumption should be identified with the Second Postulate. The Second Postulate consists in the identification of the conditions under which something counts as an object of possible experience with the conditions under which something falls under the category of actuality. And it is this last identification, not the assumption about the conditions under which something counts as an object of possible experience, that would be rejected by a transcendental realist. What a transcendental realist would reject is not the claim that something is an object of possible experience if and only if it is possible for us either to perceive it directly, or to infer its existence from what we have directly perceived, but rather the claim that something falls under the category of actuality if and only if it is possible for us either to perceive it directly, or to infer its existence from what we have directly perceived. And it is the first claim, not the second, upon which Kant is relying in his argument for the antithesis of the Second Antinomy. 


\section{Composition and Extension}

Some commentators think that both the thesis and the antithesis of the Second Antinomy should be interpreted as claims about the mereological structure of a particular type of substance, viz. material or spatially extended substance. Van Cleve writes that the Second Antinomy "is concerned with [...] the composition of matter", i.e. with the question "[what] is the mereological structure of matter, or of extended substances?". ${ }^{17}$ Similarly, Radner writes that "[the] subject of both thesis and antithesis is ordinary physical bodies, which are known to us primarily by our senses and which are obviously extended", ${ }^{18}$ and Strawson writes that "Kant's second antinomy is concerned with composite, space-occupying material things or substances". ${ }^{19}$ There is some textual evidence to support this interpretation of the Second Antinomy. Kant writes in an earlier section of the Antinomy of Pure Reason that the Second Antinomy arises because "reality in space, i.e. matter, is [something] conditioned, the inner conditions of which are its parts, and the more remote conditions of which are the parts of its parts, so that a regressive synthesis takes place, the absolute totality of which reason requires, which can take place in no other way than through a complete division, in which the reality of matter disappears either into nothing or into that which is no longer matter, namely, the simple" (A413/B440).

Other commentators think that while the antithesis of the Second Antinomy should be interpreted as a claim about the mereological structure of spatially extended, material substance in particular, the thesis should be interpreted as a claim about the mereological structure of substance in general. Grier writes that "[the] thesis proposition proceeds with a conception of composite substantiality which is prior to or abstracted from space, whereas the antithesis proceeds with a conception of substance as necessarily occupying (or conditioned by) space". ${ }^{20}$ She also writes that "the kind of composite under consideration [in the antithesis] is far less general than in the thesis" since "the antithesis is [...] specifically about matter, understood as extended substance". ${ }^{21}$ This is "confirmed by Kant's repeated references in the antithesis to the composite as 'body' and/or 'matter'”.22 Similarly, Falkenburg writes that whereas "[the] concept of space plays no role in

17 1999, 62.

$181998,427$.

$191966,183$.

20 1998, 52.

21 1998, 57.

22 1998, 65. 
the proof of the thesis", ${ }^{23}$ "[in] the proof of the antithesis the part-whole relation is interpreted spatially from the outset". ${ }^{24}$ In support of this interpretation it may be pointed out that in the first sentence of Kant's Remark on the Antithesis of the Second Antinomy, Kant refers to the antithesis as "this assertion of an infinite division of matter" (A439/B467). By contrast, there is no mention of matter in Kant's Remark on the Thesis of the Second Antinomy.

At least one commentator takes an even more nuanced approach. Malzkorn thinks that while A1 should be interpreted as a claim about the mereological structure of spatially extended, material substance in particular, T1, T2 and A2 should be interpreted as claims about the mereological structure of substance in general. He writes: "Kant makes use of the specific properties of space and spatial objects in his proof of [A1], so that [A1] is proved only for such objects; by contrast [A2] is proved without recourse to the specific properties of spatial objects and hence is also proved for non-spatial objects". ${ }^{25}$ In support of this interpretation it may be pointed out that in his Remark on the Antithesis of the Second Antinomy, Kant writes that "the second dialectical assertion [i. e. A2] has this peculiarity, that it is opposed to a dogmatic assertion, that [...] undertakes to prove in an object of experience the actuality of what we ascribed above merely to transcendental ideas, namely the absolute simplicity of substance, namely that the object of inner sense, the I, which thinks, is an absolutely simple substance" (A443/B471). ${ }^{26}$ Kant clearly thinks that A2 is contradicted by the claim that there is in the world a simple and immaterial, i.e. not spatially extended, substance, viz. the self. So it cannot be true that what he means by A2 is the claim that there is in the world no simple and spatially extended substance.

There is an assumption that is common to all of the commentators that I have mentioned so far. This is that A1 should be interpreted as a claim about the mereological structure of spatially extended, material substance in particular, and not as a claim about the mereological structure of substance in general. I think that this assumption is false. To explain why, it is necessary to look in a little more detail at Kant's argument for A1:

$232000,230$.

24 2000, 230. It is difficult to classify Engelhard's interpretation. On the one hand, she appears to think that both the thesis and the antithesis should be interpreted as claims about material substance. On the other hand, she thinks that there is an important difference between Kant's arguments for the thesis and the antithesis inasmuch as the argument for the thesis ignores the spatiality of material substance, while the argument for the antithesis takes the spatiality of material substance as its starting point (2005, 205f.).

25 1999, 169.

26 Schmiege has drawn attention to the importance of this passage. See Schmiege 2006, 274. 


\begin{abstract}
Suppose that a composite thing (as substance) consists of simple parts. Since all external relation, therefore all composition of substances, is only possible in space, the space that the composite occupies must consist of just as many parts as the composite itself. Now space consists not of simple parts but of spaces. So every part of the composite must occupy a space. But the absolutely first parts of everything composite are simple. So the simple occupies a space. Now since everything real that occupies a space contains in itself an externally related manifold, and is therefore composite, and indeed a real composite, not of accidents (for these cannot be external to one another without substance) therefore of substances, the simple would be a substantial composite, which contradicts itself. (A435/B463).
\end{abstract}

One of the premises of this argument is that if a composite substance consists of simple substances, each of the simple substances of which it consists is spatially extended. As I understand it, one of the main motivations for thinking that Kant's argument for A1 is concerned with the mereological structure of material, spatially extended substance is that if it is concerned instead with the mereological structure of substance in general, this premise of his argument is implausible. Suppose that what Kant means by a composite substance that consists of simple substances is in fact a spatially extended composite substance that consists of simple substances. Then it is plausible that each of the simple substances of which the composite substance consists must also be spatially extended. Now suppose instead that what Kant means is a composite substance that consists of simple substances irrespective of whether this composite substance is spatially extended. Then it is hard to see any reason why each of the simple substances of which it consists must be spatially extended.

The reason why I think that A1 should be interpreted as a claim about the mereological structure of substance in general, not as a claim about the mereological structure of spatially extended substance in particular, is that Kant is perfectly prepared to accept the claim that if a composite substance consists of simple substances, each of the simple substances of which it consists must be spatially extended. And the reason why I think that Kant is perfectly prepared to accept this claim is that the first premise of his argument for A1 is precisely the claim that every composite substance in the world is spatially extended. He writes: "[since] all external relation, therefore all composition of substances, is only possible in space, the space that the composite occupies must consist of just as many parts as the composite itself" (A435/B463). I suggest that Kant's claim that all composition of substances is only possible in space should be interpreted as the claim that if some substances constitute a composite substance, each of these substances occupies a part of space (and none of these substances occupies the same part of space as any other). And I suggest that, as far as Kant is concerned, this is equivalent to the claim that every composite substance in the world is spatially extended. 
To understand why Kant thinks that every composite substance in the world is spatially extended, it is helpful to consider Broad's objection against this claim:

I do not accept Kant's statement that the notion of a compound substance applies only to extended objects. I can quite well conceive of an unembodied mind, and such a mind might fairly be called an unextended substance. I can also quite well conceive of a group of such minds, communicating with and influencing each other telepathically. [...] Such a group of closely inter-related unembodied minds might fairly be called a compound spiritual substance, though not of course a compound mind. And it would be unextended. ${ }^{27}(1954,18)$

The first point to make in response to Broad's objection is that it is neither here nor there whether it is possible to conceive of a composite substance that is not spatially extended. Kant's argument is about substances in the world. And as I explained in Section 2, what Kant means by the world in the context of the Second Antinomy is the sensible world, which he identifies with the totality of possible experience. So the important question is whether a composite substance that is not spatially extended is something of which it is possible to have experience. ${ }^{28}$ The second point to make in response to Broad's objection is a little more complicated. As far as Kant is concerned, to have experience of a composite substance is to have experience of a manifold of substances in a particular relation, viz. the relation of composition. Now Kant thinks that if I am to have experience of a manifold, I must represent this manifold as ordered either in time or in space. ${ }^{29}$ A manifold is ordered in time if and only if the elements of this manifold exist at different times. And a manifold is ordered in space if and only if the elements of this manifold exist in different places. The crucial question is whether it is possible to represent a manifold of substances that stand in a relation of composition as ordered in time. I suggest that Kant's answer to this question is No. Kant

\section{$271954,18$.}

28 It should be noted that it doesn't immediately follow from the fact that Kant's argument is concerned with substances in the sensible world that it is concerned with spatially extended substances. For Kant, what follows from the fact that an object is in the sensible world is that it is either in space and time (an external object), or in time alone (an internal object). According to the interpretation that I am defending, the point of the first stage in Kant's argument for A1 is to show that a composite substance cannot count as being in the world just in virtue of being in time. It must also count as being in the world in virtue of being in space.

29 At the beginning of the Transcendental Aesthetic, Kant defines the form of appearance as "that in virtue of which the manifold of appearance can be ordered in certain relations" (A20/ B34), and he goes on claim that there are two forms of appearance, viz. space and time (A22/B36). Space is "the form of all appearances of outer sense" (A26/B42), while time is "the form of inner sense" (A33/B49). I take it that this is supposed to imply that if a manifold is intuited as ordered in a relation it must be represented either as ordered in space or as ordered in time. 
thinks that the substances that stand in a relation of composition must co-exist. He thinks that they must be represented as existing at the same time. He doesn't think that they can be represented as existing at different times. So he thinks that they must be represented as existing in different places. From this it follows that if a composite substance in the world consists of simple substances, each of the simple substances of which it consists must occupy a part of space (and none of these simple substances can occupy the same part of space as any other). I suggest that it is precisely this line of reasoning that Kant has in mind when he writes in his argument for A1 that "[since] all external relation, therefore all composition of substances, is only possible in space, the space that the composite occupies must consist of just as many parts as the composite itself" (A435/B463). What Kant means by an external relation of substances in this context is precisely a relation between substances that exist at the same time.

Even if some of the details of this reconstruction are incorrect, that doesn't affect the main point, which is that Kant's argument for A1 begins with an argument for the premise that if a composite substance consists of simple substances, each of the simple substances of which it consists occupies a part of space. To this it may be objected that in the relevant sentence of his argument for A1, Kant is presupposing that the composite substance he is talking about is spatially extended. But if Kant is presupposing that the composite substance he is talking about is spatially extended, it is not at all clear what he is doing in the first clause of this sentence. What is the point of his claim that "all external relation, therefore all composition of substances, is only possible in space" (A435/B463), if he is only talking about spatially extended composite substance?

I conclude that while it is true that part of Kant's argument for A1 is supposed to establish a claim about the mereological structure of spatially extended substance in particular, viz. the claim that there is no spatially extended composite substance in the world that consists of simple substances, it doesn't follow from this that Kant's argument for A1 is not supposed to establish a claim about the mereological structure of substance in general. For the point of the first step in Kant's argument for A1 is to establish that every composite substance in the world is spatially extended, from which it follows that if there is no spatially extended composite substance in the world that consists of simple substances, there is no composite substance in the world that consists of simple substances.

There is one final point that I want to make about the role of spatial extension in Kant's argument for the antithesis of the Second Antinomy. It has been suggested by Buroker that the difference between Kant's argument for A1 and his argument for $\mathrm{A} 2$ is that whereas the former is simply an argument against material, spatially extended simple substances, the latter is also an argument against immaterial, mental substances (2006, 242-244). One might connect this 
to a distinction that Kant draws in his Remark on the Thesis of the Second Antinomy between two types of simple substance: atoms, which are plausibly spatially extended, material substances, and monads, which are not (A441f./B469f.).

I do not think that this interpretation is quite correct. It should be noted, first of all, that Kant does not define atoms and monads in terms of whether or not they are spatially extended. He defines a monad as "the simple that is given immediately as simple substance [...] and not as element of the composite" (A442/ B470), and he defines an atom as a simple substance that is given as an element of a composite substance. Second, it should be noted that it is precisely this mereological difference between simple substances that is reflected in Kant's arguments for A1 and A2. The argument for A1 is an argument against simple substances that are parts of composite substances, and the argument for A2 is also an argument against simple substances that are not parts of simple substances. The reason why the two arguments also differ inasmuch as Kant's argument for A1 involves spatial extension, whereas his argument for A2 does not, is that Kant thinks it is a consequence of the special mereological feature of atoms, viz. that they are parts of composite substances, that they must be spatially related. Kant's argument for A2 doesn't involve spatial extension because he doesn't think that there is any reason to assume that isolated simple substances must be spatially related.

\section{Extensive Magnitude}

As I explained in Section 3, one of the premises of Kant's argument for A1 is that

(1) Every composite substance in the world is spatially extended.

This is the point that Kant is making when he writes: "all composition of substances [...] is possible only in space" (A435/B463). It is widely accepted that one of the other premises of Kant's argument for A1 is that

(2) Every spatially extended substance in the world is a composite substance.

This is what Kant means when he writes: "everything real that occupies a space, contains in itself an externally related manifold, and is therefore composite [...]" (A435/B463). The last assumption that I am going to discuss in this article has to do with the remaining premise of the argument, which is that 
(3) If a composite and spatially extended substance in the world consists of simple substances, each of the simple substances of which it consists is spatially extended.

Kant's argument for A1 runs as follows: Suppose that there is a composite substance in the world that consists of simple substances. By (1), this composite substance is a composite and spatially extended substance that consists of simple substances. By (3), each of the simple substances of which this composite and spatially extended substance consists is spatially extended. So there must be simple substances in the world that are spatially extended. But by (2), these simple substances must be composite substances. And that is absurd. Hence if (1), (2) and (3) are true, it must be true that no composite substance in the world consists of simple parts. ${ }^{30}$

Some commentators think that premise (3) of Kant's argument for A1 is based on a principle about the relationship between the size of the extension of a composite substance and the sizes of the extensions of the substances of which the composite substance consists. These commentators assume that a substance is spatially extended if and only if the size of its extension is strictly greater than zero and that a substance is not spatially extended if and only if the size of its extension is zero. And they think that premise (3) of Kant's argument is based on the principle that it is impossible to make a composite substance the size of the extension of which is strictly greater than zero out of any number of substances the size of the extension of which is zero. One prominent example is Van Cleve, who writes that Kant's premise "rules out the possibility that composite substances are composed of unextended simple parts, or what Bayle called mathematical points", and that

[Kant's] reason for ruling [this] out is not that there could not be such entities as [mathematical] points, but rather that such entities could never 'fill space through their mere aggregation' (A440/B468). The basic intuition here was forcibly expressed by Bayle: '[P]ersons of the slightest depth can comprehend with complete certainty, if they give the matter a little attention, that several nonentities of extension joined together will never make up an extension. ${ }^{31}$

30 It is widely accepted that Kant's argument for A1 is based on premises (2) and (3). According to Falkenburg, for example, the key premises of the argument are that "every simple part of the composite must be [...] extended", and that everything extended is composite $(2000,236)$. And according to Van Cleve, the key premises are that "[every] part of a composite substance occupies a space”, and "[whatever] occupies a space is composite" $(1999,65)$. See also Grier 2001, 207 f., Falkenburg 2000, 183 f., and Radner 1998, 42.

31 1999, 65. 
Similarly, Radner writes that Kant's argument for A1 turns on the principle that "the parts [of a composite] must add up to the whole space occupied by the body, and in order to add up to a finite (nonzero) extension, each part must have finite (nonzero) extension”.32,33

I suggest that there are two good reasons to reject the assumption that Kant's argument for A1 turns on this principle. The first reason is that there is no evidence in the text that considerations about the sizes of the extensions of substances play any part in Kant's argument for A1. There is certainly no hint of Bayle's claim that "several nonentities of extension joined together will never make up an extension”. Van Cleve does quote a passage of text when he discusses the relevant aspect of Kant's argument for (1). He writes that Kant rules out the possibility of a composite substance that consists of simple substances that are not spatially extended on the grounds that such substances could never "fill space through their mere aggregation" (A440/B468). But the passage of text that Van Cleve is quoting at this point does not appear in Kant's argument for A1. In fact, it appears in his Remark on the Antithesis of the Second Antinomy. Here Kant writes that those philosophers who object to the claim that matter is infinitely divisible proceed "as if it were possible [...] to treat the determinations of space a priori as not at the same time applying to what is possible only insofar as it fills space" (A439/B467). These philosophers accept the claim that space is infinitely divisible. But they reject the claim that matter is infinitely divisible. So they must think that it is possible for space to have a particular property, viz. infinite divisibility, even if matter, i.e. that which is possible "only insofar as it fills space", lacks this property. It is in the very next sentence of his Remark on the Antithesis of the Second Antinomy that Kant writes: "[if] one listens to them [i.e. to these philosophers], one must, apart from the mathematical point, which is simple, but is no part, merely the boundary of space, still think of physical points, which are also simple, but like parts of space have the advantage of filling space

32 1998, 428. Michael Friedman thinks that the parallel argument in Kant's pre-Critical Physical Monadology turns on the same principle. He writes that "Kant's reliance on Zeno's metrical paradox is clear in Proposition IV of the Physical Monadology (that a composite divisible to infinity does not consist of primitive simple parts)" $(2013,162)$. According to Zeno's paradox, "one can never attain an extended region of space by composing any number of unextended simple elements (points), not even an infinite number of such elements" $(2013,162)$.

33 Van Cleve considers an objection to this principle based on subsequent developments in mathematics $(1999,66)$. He draws attention to Adolf Grünbaum's claim that, according to the standard approach to the determination of the sizes of parts of space since the early $20^{\text {th }}$ Century, it is perfectly possible for a spatially extended thing to consist of things lacking in spatial extension, as long as the number of these things lacking in spatial extension is uncountably infinite. See Grünbaum 1952. For a helpful recent discussion of Grünbaum's work, see Ehrlich 2014. 
through their mere aggregation”. Kant goes on to write: “[now] without repeating here the standard, clear refutations of this absurdity [...]” (A439/B467). Now Van Cleve thinks that what Kant is describing as absurd in this passage is the idea that it is possible for a composite and spatially extended substance to consist of simple substances that are not spatially extended. But this is not true. It is clear from the context of the passage that what Kant is talking about is the idea that the mereological structure of spatially extended substance is not the same as the mereological structure of space. His basic point is that the philosophers who object to the infinite divisibility of matter think that although there are no simple parts of space, there are spatially extended simple substances. I suggest that when Kant adds that these philosophers assume that the simple substances in question "have the advantage of filling space through their mere aggregation", he is accusing them of inconsistency. On the one hand, they are committed to rejecting the assumption that the mereological structure of spatially extended substance is the same as the mereological structure of space. On the other hand, they want to rely on this assumption. Specifically, they want to rely on the assumption that the extension of a composite substance consists of the extensions of the substances of which this composite substance consists, which implies that it is possible to make a substance that fills a part of space by adding together substances that fill the parts of this part of space. I suggest that this is what Kant means by simple substances "having the advantage of filling space through their mere aggregation”. If this is correct, the passage that Van Cleve quotes does not support the assumption that Kant's argument for A1 turns on the principle that it is impossible to make a composite substance the size of the extension of which is strictly greater than zero out of any number of substances the size of the extension of which is zero.

The second reason to reject the assumption that Kant's argument for A1 turns on this principle has to do with the concept of spatial extension. The assumption is plausible only if what Kant means by the claim that a substance is spatially extended is that this substance has an extension the size of which is strictly greater than zero. It is plausible only if Kant has what I shall call a metrical conception of spatial extension. But there is good reason to think that this is not how Kant understands the concept of spatial extension at all. It should be clear from the passages that I quoted at the beginning of this section that, for Kant, the claim that a substance is spatially extended is the claim that it "occupies a space". ${ }^{34}$ Now one of the premises of Kant's argument for A1 is that "space consists not

34 There is direct textual evidence for this in Kant's Metaphysical Foundations of Natural Science, where he writes that it "can be said of every geometrical figure, that it occupies a space (it is extended)" (4:497). 
of simple parts but of spaces" (A435/B463). Here Kant contrasts the concept of a space with the concept of a simple part of space. And this suggests that what Kant means by a space is a part of space that is not a simple part, i.e. a composite part of space. What Kant means by a substance that occupies a space is not a substance the size of the extension of which is strictly greater than zero, but rather a substance the extension of which is a composite part of space. So it appears that Kant has what I shall call a mereological conception of spatial extension. To be spatially extended, for Kant, is to have an extension that is not a simple part of space. If this is correct, it is implausible that Kant's argument for A1 turns on a principle about the relationship between the size of the extension of a composite substance and the sizes of the extensions of the substances of which it consists.

It should be noted that it doesn't follow from what I have argued in this section that Kant would not accept the principle that it is impossible to make a composite substance the size of the extension of which is strictly greater than zero out of any number of substances the size of the extension of which is zero. I suggest that this principle is one that Kant would accept, but not for the same reasons as Bayle. In particular, I suggest that Kant would accept this principle simply because he rejects the possibility of a substance the size of the extension of which is zero. In the Anticipations of Perception, Kant defines continuity as "the property of magnitudes according to which no part of them is the smallest possible (no part is simple)". He then adds that "space and time are quanta continua" (A169/B211). Notice first that Kant identifies the claim that no part of space is the smallest possible with the claim that no part of space is simple. Presumably, his thought is that if a part of space is not simple, i. e. if it has a proper part, there is a smaller part of space, viz. the proper part. So if no part of space is simple, no part of space is the smallest possible. Second, notice that if no part of space is the smallest possible, there can be no part of space the size of which is zero. For there can be no part of space smaller than a part of space the size of which is zero. Putting these two points together, it is reasonable to think that Kant would rule out the possibility of a substance the size of the extension of which is zero - and therefore the possibility of a composite substance the size of the extension of which is strictly greater than zero that is made up of substances the size of the extension of which is zero - precisely because he thinks that no part of space is simple. He would accept Bayle's principle on the basis of his assumptions about the mereological structure of space. By contrast, Bayle's acceptance of the principle is not based on any assumptions about the mereological structure of space. It is based instead on the thought that, even if there are substances with an extension the size of which is zero, no number of these substances added together would be enough to make a substance the size of the extension of which is greater than zero. It is this 
thought that I do not think plays any part in Kant's argument for A1. And I am not aware of any evidence that it is a thought that Kant accepts.

\section{Conclusion}

In the course of this article I have argued against three widespread assumptions about Kant's argument for the antithesis of the Second Antinomy. I have argued against the assumption that Kant's argument for A2, i.e. the claim that there is no simple substance in the world, is logically independent of his argument for A1, i.e. the claim that no composite substance in the world consists of simple substances, on the grounds that abandoning this assumption allows us to solve two puzzles about the structure of Kant's argument for the antithesis as a whole. I have argued against the assumption that A1 should be interpreted as a claim about the mereological structure of spatially extended substance in particular, as opposed to a claim about the mereological structure of substance in general, on the grounds that Kant's argument for A1 begins with the premise that every composite substance in the world is a spatially extended composite substance. Finally, I have argued against the assumption that Kant's argument for A1 is based on the principle that it is impossible to make a composite substance the size of the extension of which is strictly greater than zero out of any number of substances the size of the extension of which is zero on the grounds that, first, there is no textual evidence to support this interpretation, and second, it conflicts with the fact that Kant has a mereological, as opposed to a metrical, conception of spatial extension.

In the introduction to this article I claimed that these assumptions stand in the way of a proper assessment of Kant's belief that this argument is sound if and only if transcendental realism is true. I also claimed that these assumptions mask the relevance of this argument to more recent philosophical debates about the mereological structure of space and the mereological structure of spatially extended things. This is true of the third assumption in particular. It should be clear from what I have established in this article that Kant's argument for A1 is based on a number of claims of interest to philosophers today. It is based on the claim that "space consists not of simple parts, but of spaces" (A435/B464), i.e. the claim that space is what David Lewis calls "atomless gunk", ${ }^{35}$ as well as the claim that the mereological structure of spatially extended substance is the same

35 1991, 20. 
as the mereological structure of space itself, which is the basic intuition behind principles of "mereological harmony". ${ }^{36,37}$

Broad, C. 1954. “Kant's Mathematical Antinomies”. Proceedings of the Aristotelian Society 55, $1-22$.

Buroker, J. 2006. Kant's Critique of Pure Reason: An Introduction. Cambridge.

Ehrlich, P. 2014. “An Essay in Honor of Adolf Grünbaum's Ninetieth Birthday: A Reexamination of Zeno's Paradox of Extension”. Philosophy of Science 81, 654-675.

Engelhard, K. 2005. Das Einfache und die Materie: Untersuchungen zu Kants Antinomie der Teilung. Berlin.

Falkenburg, B. 2000. Kants Kosmologie: Die wissenschaftliche Revolution der Naturphilosophie im 18. Jahrhundert. Frankfurt am Main.

Friedman, M. 2013. Kant's Construction of Nature: A Reading of the Metaphysical Foundations of Natural Science. Cambridge.

Grier, M. 2001. Kant's Doctrine of Transcendental Illusion. Cambridge.

Grünbaum, A. 1952. "A Consistent Conception of the Extended Linear Continuum as an

Aggregate of Unextended Elements". Philosophy of Science 19, 288-306.

Guyer, P. 1987. Kant and the Claims of Knowledge. Cambridge.

Lewis, D. 1991. Parts of Classes. Oxford.

Malzkorn, W. 1999. Kants Kosmologie-Kritik: Eine formale Analyse der Antinomienlehre. Berlin. Radner, M. 1998. "Unlocking the Second Antinomy: Kant and Wolff". Journal of the History of Philosophy 36, 413-441.

Schaffer, J. 2009. "Spacetime the One Substance”. Philosophical Studies 145, 131-148.

Schmiege, 0. 2006. "What is Kant's Second Antinomy About”. Kant-Studien 97, 272-300.

Strawson, P. 1966. The Bounds of Sense: An Essay on Kant's Critique of Pure Reason. London. Uzquiano, G. 2011. “Mereological Harmony”. Oxford Studies in Metaphysics 6, 199-224.

Van Cleve, J. 1999. Problems from Kant. Oxford.

Van Inwagen, P. 1990. Material Beings. Ithaca/London.

36 Uzquiano characterizes mereological harmony as the intuition that "mereological relations on material objects mirror and are mirrored by parallel mereological relations on their exact locations" $(2011,200)$. He takes the term from Schaffer, who puts forward an argument based on the premise that "[the] geometrical and mereological properties of material objects are a perfect mirror of the geometrical and mereological properties of their containing spacetime regions" $(2009,138)$.

37 I would like to thank two anonymous referees for their helpful comments. I would also like to thank Martin Pickup, Stefan Sienkiewicz, Andrew Stephenson, James Studd, and Irwin Zaid. 